\title{
The social weaving of a reading atmosphere
}

\author{
Paula Sequeiros \\ University of Porto, Portugal
}

\begin{abstract}
This paper discusses how public library readers in Almeida Garrett, Porto, create a reading atmosphere, focusing on meanings associated with aural conditions. Through a qualitative, single case study, ethnographic and interview techniques were applied. Readers' actual practices and discourses, through a theoretical sample, and those of managers, staff and architects were analysed; a spatial analysis was conducted within the framework of social inequalities and power relations. The paper proposes the concept of reading atmosphere and suggests that its social production is based on a tacit, informal code of conduct in which some regular readers played an influential role. Some recommendations on service provision are made.
\end{abstract}

\section{Keywords}

behaviour, noise, public library, regulations, social classes, space

\section{Introduction}

Social space is the product of economic, social and political life. Concrete in its physical dimension, the social relations that produce and reproduce it are however less obvious and must be unveiled through social analysis (Lefèbvre, 2000). Space allows for, suggests or inhibits actions, in an intricate game of power relations. Diverse social spaces may then superpose, interpose or contend. In everyday life, users appropriate space and practice it while making places, occasionally circumventing constraints and strategic measures through tactical tricks (Certeau, 1990).

Departing from this theoretical framework, the author sought to understand how a library's architectural design may shape reading practices, allowing for or inhibiting the appropriation of space and the creation of particular reading atmospheres and how readers interact with it. Particular attention was paid to the production and/or toleration of noise made by other readers and to understand 'what do they mean when they speak of noise'?

Methodologically, an integrated, qualitative approach was used to analyse and interpret those practices (Blumer, 1969; Geertz, 1975) and also their wider context of relations and processes, as well as the socially constructed meanings attached to them by subjects, to achieve a comprehensive understanding of the whole social reality (Donmoyer, 2000).

An interesting, rich case was chosen, Almeida Garrett public library in Porto, drawing on Michael Burawoy's extended case method (1998). This single case methodology emphasizes the transferability of knowledge produced from singular situations, as opposed to the more traditional concept of generalizability, tied to the statistical analysis of great amounts of quantitative data collected from several cases. If all scientific knowledge may be treated as working hypotheses subject to being falsified, in Lakatos' terms (1978) then a resemblance between contexts may call for its transfer on the basis of fittingness of conclusions. Just as individuals accumulate personal knowledge and enrich repertoires drawing from vicarious experiences, so can the social sciences draw on the results of single cases by eliciting new questions and by theory addition (Donmoyer, 2000).

The research design followed an approach which allowed the understanding of this reality without imposing prior expectations on phenomena or situations (Burawoy, 1998; Patton, 1990), and which fostered the emergence of unexpected information or unforeseen relations between data. Nevertheless, and following Burawoy's line of thought, it is assumed that new theories are partially constructed from previous ones, requiring reflexivity and intersubjectivity which may establish the basis for dialogue

\section{Corresponding author:}

Paula Sequeiros, R António Cardoso, 2652 P, 4|50-08I Porto, Portugal Email: psequeiros@gmail.com 
among subject and objects of knowledge, here understood as observant and participants, on the one hand. On the other hand, there is also an awareness of the importance of an attitude focusing on theories of the observed in the field, on their practices, speech and productions, while taking into account their values and meanings in the very situations they may occur (Taylor and Bogdan, 1984).

With these objectives and principles in mind, a theoretical sample was constructed according to the perceived diversity in that library and according to gender, age, social class, ethnic origin, disabilities: 28 users, two library managers, one assistant librarian, the maintenance supervisor, and the architect were interviewed. Michael Burawoy's extended case method (1998) was applied.

The empirical research design focused on readers' actual practices and discourses, as well as on those of librarians, staff and architects, alongside with the building analysis all in a framework of social inequalities and power relations. Seeking a strong ethnographic approach, observation (Seale, 2004) and interview (Kvale, 1996) techniques were applied. Young children were analysed by means of informal conversations with them and their relatives and they were requested to draw a library (Gubrium, 2002). Field work started at the end of 2008 and research was continued into other aspects and dimensions of this library's use until mid 2009.

Some early results from a wider ongoing research are now available and a specific topic was selected as a focus: how readers create and integrate or modify a particular public reading atmosphere, and how they evaluate it, considering the physical, sensorial, emotional and social dimensions of the issue.

The author assumes a compromise with the intentionality of the constructed object and with the purposes of the research (Haraway, 1991) and favours the provision of democratic spaces for public reading as a relevant public service, to be enjoyed for conviviality, culture, leisure, information or learning by all citizens alike. Accordingly, practical recommendations are made in order to improve reading conditions and to provide a welcoming environment to all social groups using this library.

\section{The Almeida Garrett Public Library}

In order to avoid a superficial analysis of space, limited to and by visibility, Lefèbvre suggested that space be researched according to the three concepts of form, structure and function, taking into account both the space of representations and the representations of space (2000). In the description below, his conceptualization is used albeit acknowledging that social reality is a complex one and that these conceptual divisions, although useful for research purposes, bear the marks of analytic, thinking tools, dissecting and separating what is tied and intertwined 'in the real world'. Further on in the paper, the analysis is developed based on the 'trialectics of space', a term coined by Edward Soja (1996) to describe Lefèbvre's approach.

Inaugurated in 2001, when Porto was a European Capital of Culture, the Almeida Garrett library was designed to be built within Porto's then largest public park. Of 19th-century Romantic design, the park has rose gardens, lakes, large trees, and a magnificent view over the Douro River's estuary. The park is a frequent destination for visitors going to the sports pavilion, the restaurant and the children's park, all built in the first half of the 20th century. The area is well served by public transport, and is equidistant from both city centres; the historical and the more modern one. Nevertheless, its location within the park isolates readers from the usual urban bustle.

The library reveals its power of attraction in that only a half of the interviewees reside in the city area.

\section{Function}

José Manuel Soares, its architect, stated that his wish was to bring the garden into the library, while not imposing a building in it. He also wished to control the incoming light without affecting its relation with the surrounding area or effacing the particularities of the place. From his point of view, the most important concepts in the architectural programme were free access to stacks, and the demand for a library for 'those who are about to have a first contact with books', for students at a time when school libraries were still scarce, where everyone might come in or out freely, 'in continuity with the public space'. His concerns were directed at designing a space flexible enough to be 'ready to be used in different ways', allowing for the appropriation of particular small spaces while discouraging dispersion, 'according to each time period', 'that could still be adapted over time', a space that might be 'clearly put under questioning'. He stressed the importance of full cooperation from all departments, from the Culture councillor and the support of the National Book Institute. European Union funding allowed resources for the use of high quality materials and the search for innovative solutions.

\section{Form}

As an example of the use of high quality materials, pure white imported marble was used in the lobbies and the staircase, while in search for innovative solutions, rows of half pine tree logs, in a brutalist manner, treated according to research done at the local public university, were used as a curtain in front of the main façade, made of special UV filtering glass. Light coloured wood was selected for the remaining floors, to line the interior walls and for furniture; the upper parts of the walls were painted white. Simple, pure lines and well defined surfaces dominate. The ceiling has a wave-like design to improve aural conditions. 
The insertion in the texture of the city may be perceived through the apertures in the back façade from where the houses in the street can be sighted 'full of light all day long', in the architect's words. 'On one hand, sense of orientation, not like those brutal shopping-centres where people get disoriented ... On the other hand, a sense of unity of space. But then again the capacity to form different qualities of space, really different, within this big one, as it is!'.

Similarly, Eigenbrodt (2008: 101) stresses the importance of guaranteeing 'communication, access, orientation and freedom of movement' as particular spatial requirements when 'designing library facilities for everyone'.

\section{Structure}

The library occupies two of the four levels of the building, whilst the art gallery, the auditorium and the garage and technical area occupy the other two. The entrance lobby is divided into two floors, and a marble staircase leads to the reception desk. The continuum effect along the whole building still allows for separate although not isolated areas, designed for general reading, for children, for newspaper reading, for multimedia and Internet workstations. A cafeteria, the toilets and the children's area are placed on a slightly lower level. An exterior patio mediates the space between the cafeteria and the children's area, so that carers may sit and have a coffee and still be able to watch over their children. Visibility of the whole surface of each floor is achieved. Alongside the children's section runs a corridor leading to the adults' reading areas, occupying that same floor and a lower one. A glass screen, not reaching the ceiling, separates the first third of the area, to reduce the noise from the children's activities. At the end of the corridor is the newspaper corner with sofas, tables in sets of two or four by the front and back façades. At the far end, double lines of facing tables are to be found as well as an area with computers and Internet access. In the middle, a mezzanine creates a large hole in the floor, revealing a lower level for multimedia and more Internet stations.

The hierarchy of spaces was strategically used to create decreasing noise levels as one progresses in the building, still allowing for a global reading of the whole space. The architect wanted, above all, to dissociate the distribution of spaces through the different floors and between the library and the gallery, from any hierarchical connotation.

\section{General user evaluation of the library space}

[...] they may not have much light, both the library and the gallery. That was the difficulty, achieving a relation with what is going on around and the specificity of the place. It's the kind of thing that people don't notice but that is what imprints character to it (José Manuel Soares, the architect).
The building's insertion in the park is appreciated, since 'you can see that it's integrated in Nature', and, occasionally, you may stroll there to 'ease your mind', according to readers' words.

In fact, the difficulty of referring to and of evaluating space, a reality which is simultaneously abstract and concrete (Lefèbvre, 2000: 134-135), was a constant throughout all the interviews with users.

So too were the references to the quality of experiences propitiated by space, which readers frequently mentioned in their discourses. Alongside qualifying the building as 'well achieved architecture', 'wide, 'you can walk through at ease with [...] no obstacles', 'all very pleasant', 'cosy', 'one of the best things Porto has', very frequent references were made to it being 'full of light' and 'transparent' which are interpreted as having more to do with the reading social atmosphere than to the building or the lighting themselves. Curiously, a female reader living in a therapeutic community was the only person to refer negatively to the building: 'the atmosphere is too standardized [...], a true rigidity, $[\ldots]$ the building restricts, [...] I was the one who had to adapt'. These emotions should be interpreted, from the author's view, as deriving from the uneasiness she felt to be in a public space. Being among strangers seemed to represent an effort in the course of the therapy she is going through.

Luminosity and transparency are taken here as synonymous with feelings of openness and tranquillity. According to Lefèbvre (2000: 152), space, being so abstract, frequently figures in discourse through rhetorical devices that reflect 'the predominance of vision, of the visible, the legible', obscuring social relations and the way space and power intertwine. Luminosity and transparency are also the best translation into an architectural expression of the concept of free and unhindered access commissioned in the architectural programme.

Silence in the library is a frequently addressed theme (Bertrand, 1994; Finlayson, 2008; Mattern, 2007; Miribel, 2007), although empirically based research seems to be almost nonexistent. Noise making, though, is a central theme in cliché anecdotes and common sense statements associated with libraries. Cell phones ringing are clearly what disturb some readers the most in this particular case of Almeida Garrett, with staff being frequently asked to intervene so that silence may resume. The noise of high heels also has a negative effect and disapproving looks would be directed to those making it. Noise produced by children tends to be more tolerated than other kinds of noise; several young and adult readers made a point of stating that they felt the presence of infants to be important.

Respondents' social class often framed their comments. and readers without a home or with a deficient one showed to be much less demanding as far as comfort levels were concerned. One stated: 
This is the best environment there is, though sometimes there are some people here who don't know how 'to be' [in such a place], well, we know that it's the same everywhere, but then you forgive them, you accept them, they also have the right to be here.

Questioned as to whether he had ever admonished anyone, he answered: 'I did, but it was settled then and so one forgets'. And then he was questioned about staff intervention: 'They do, they intervene and are polite, they have manners, yeah... they also make demands, one can see they are "en su sítio" like the Spaniards say...' (male retired reader, former bank clerk, 72, a resident).

Curiously, the most bitter complaints about noise are clearly associated with practices judged to be out of place and to people labelled as those who 'don't know how "to be" in libraries. Complaints are really directed to the uniformization of attitudes around the standard of the learned reader, the habitue, the one who knows and abides by tacit rules shaped according to 'estimated legitimate practices' (Bourdieu and Darbel, 1966) and expects others to abide too, which relates to notions of what is the accepted thing to do in such a place, with all the correlated social class embodied cues. This library, like others in Portugal (Fortuna et al., 1999; Freitas et al., 1997), is predominantly used by students and intellectual or skilled professionals; manual workers are not even listed in the classification of jobs used in new readers' applications, and the upper class is absent too.

Anne-Marie Bertrand (Bertrand, 1994) reflects on the connection between noise levels and the expected role of a library, remarking that along with architectural and regulation devices, social control is probably the most efficient form of noise control in a library. She also remarks that popular sections in traditional libraries, separate from erudite sections, are noisier that the latter. So, advocating for non-enclosed, open-space libraries requires re-centring the debate on library purposes and on library models deriving from them.

This is how noise making should be understood, rather than simply associated to physical, aural dimensions, but deeply associated with behaviour labelled as inadequate, as to being out of one's place or milieu.

Karin Bijsterveld's insightfully comments that " "unwanted sound" ... has often been associated with a terrifying disruption of a specific social order, whereas rhythmic and/or loud, positively evaluated sounds have been associated with strength, power, significance, masculinity, progress, prosperity and, last but not least, control' (cited by Mattern, 2007: 281). As Shannon Mattern (2007: 281) puts it, "both enforced silence and freedom from noise represent forms of power', which she intimately associates with Bourdieu's (1979) concept of habitus in that it helps to understand how socially learned, embodied predispositions rather than automatic, instinctive reflexes condition responses to architecture and media, still allowing for individual variation and personal choice.

\section{Involving space: Location and access}

The park isolates visitors from the urban landscape, providing wider views into the garden and the Douro River, just down the cliff.

'Very well located, it's wonderful, 'integrated in Nature'. Most interviewees spoke very favourably of the insertion in a garden, in spite of adult readers admitting that they rarely use it and although only children stated that they often take opportunity to stroll in the park. Knowing it is there, however, allows for a calming, pleasant sensation, although reading may be such an absorbing task that even large peacocks walking along the window sills may not be noticed, as was the case during one of the interviews.

Almost all users get to the library using public transport although some living or working nearby access it on foot.

\section{Emotions: 'Finding the words for things'}

If reading is a form of 'ubiquity', an 'impertinent absence' (Guy Rosolato, 1969, cited in Certeau, 1990: 250), this atmosphere is collectively woven from valued raw materials: tranquillity, organization, concentration, an integrative collective intellectual labour, were all mentioned by readers as the most valued aspects of a library. And these cannot be achieved by staying alone at home.

The female reader living in a therapeutic community was looking for a place with more privacy. She makes a very expressive statement:

reading is inexhaustive, [reading] means being totally absorbed, finding the words for things, to rest and reflect. [...] If I stopped leading the life I'm used to in public spaces, I would certainly lose a true pleasure and a real harmony I'm looking for.

For some, reading is associated with the pride of an accomplishment, especially for those who lived in a time when studying was a class privilege. This was the case of a female reader, and doubly so: firstly, for having the necessary educational capital, in spite of being a manual worker's daughter and secondly that, in spite of becoming blind, she was still able to read Braille at a dedicated workstation. Similarly, an elderly reader, retired and a student in a Seniors' University, was compensating for the chance he did not have when he was young. Seeing young people and children made him rejoice.

\section{Conviviality}

Co-presence is a valued dimension of public reading. Even if readers do not talk to familiar faces around them, their activities are carefully followed and this may be an opportunity to break the isolation of lonely lives. A lot of lonely people come regularly to the Almeida Garrett Library. 
The urge to mingle is felt diversely, though. Proximity without propinquity seems important to many, adding the reservedness of reading to the one characteristic of urban living, according to Webber (1963). Going to the library is not necessarily an individual act; children are almost always accompanied by carers or in school groups, some couples come in, adolescents frequently come in classmate groups or dyads.

Regular users chat with one another or with the staff; they may occasionally exchange opinions on the news headlines. A homeless reader, a former typographer for a local newspaper, says:

Above all, I like coming here a lot when I'm feeling down, I come in and it seems I reinvigorate again! Crossing that door seems like home to me, as if it were a family of my own, I feel superbly well!

A particular form of conviviality is most appreciated by students and informal scholars who value the togetherness propitiated by a collective atmosphere of order and encouragement to concentrate and work:

I myself enjoy being able to look around and say 'look, all the other people are also doing the same as I do', so [it is useful] to soften things a little [laughing] if it's something I don't like to do, that's what I try to think about (male student, 34 years old).

There are some behaviours that are more or less predictable and there is a certain intrinsic order, intrinsic to behaviours of the public, and that works ... [in helping her own study] (female student, 40).

Some social diversity seems to be appreciated; senior readers express their contentment at being able to watch younger people and children, different faces every day, a homeless male user feels the social and age diversity are invigorating, 'different faces every day'.

According to Given and Leckie (2003), talking was one of the most common activities in two central public libraries in Canada, after reading and writing, alongside computer use. No further information was gathered as to motives, themes, significance, etc., as their approach was an extensive, quantitative one. However, and probably leaning on their professional experience and sensitivity, they argue (p. 382) that "libraries may need to do more to encourage the view of "library as interactive place" versus "library as quiet space", advocating the availability of study rooms where discussing aloud might be permitted.

\section{Personalization, privacy, surveillance}

Reading is an introspective activity that creates a private bubble, soft but protecting. You do not expect to be disturbed and, along with reading skills, you also learn the rules of co-reading.
Personalized audio devices are a technological resource that many use in order to reinforce those bubbles, in order to privatize space and to control undesired interactions with others: if you are wearing earplugs you are also signalling that you do not want to be disturbed (Bull, 2006). Portable music also fulfils certain aesthetic and affective needs, allowing for the shaping of moods and intellectual energy into soundscapes (Bull, 2006) which overrun the traditional limits of private and public space, inserting breaches of isolation, privacy and personalization into shared and even crowded places. Several readers wore earplugs connected to MP3s or portable computers. Most of them brought previously selected music from home; some borrowed the library's CDs.

Students may be thought of as the kind of user most particularly entitled to silence in order to concentrate on their tasks. Some may occasionally frown at people chatting, signalling that their labour is being disturbed, but no complaints could be specifically associated with that status. On the other hand, some expressed their preference for an environment that is not completely silent, which would indeed bother them, and they also expressed their preference for a light murmur as a comfortable background noise.

The need for privacy and the meanings attached to it varied according to domestic and work life habits and, ultimately, according to social conditions and gender: the homeless reader does not mind that other people peep into his screen while he is using the Internet; a young female reader resents being observed by some men in an 'unpleasant' way. The sole question about a possible lack of privacy addressed to a young couple, living in a single social housing apartment with their two children and eight other relatives, gave way to laughter; the library was the only place they could get some privacy, they said. As Michèle Petit (2001: 118) insightfully noted:

\footnotetext{
The intimate, inner life, a concern for oneself, all that is not for them [the poor], it was a patrimony of the people with resources. [...] The absence of intimacy is maybe the best poverty indicator, even more so than income. The poorer you are, the less intimacy you get. Lower down the social scale, when you have no roof, in a street, even the minimum gesture is exposed to the public gaze.
}

Almost everyone referred to co-presence as a sort of tacit agreement, being in such a public place presupposes a certain concession over the reservation of personal space, compensated for with all its advantages.

Readers also signalled that they knew that moving chairs to a different location was not a problem. A particular case of users modifying space is narrated by the chief librarian:

We conceived that space [the mezzanine] for shelving, but right then we found that it was not very reasonable because shelves were very low [waist-height] and books could not be 
seen. Soon enough, readers solved the problem because as stacks were movable, they withdrew the shelves and leaned there [against the top surfaces] and we had to put a turned edge so that books wouldn't fall [onto the lower level]. It's one of the most coveted places in the library [...].

In Certeau's (1990: 173) definition place is: 'an instantaneous configuration of positions, implying an indication of stability, [...] an order in accord with which the elements are distributed in relations of coexistence'. Contrary to place, space 'has none of the univocity or the stability of a "proper". Still according to Certeau's thought, 'space is a practiced place’ (p. 173). Making a personalized place, even by removing furniture pieces, was an accepted practice in the library and, by doing so, readers were also producing space through their personalized appropriations.

Different strategies to appropriate space could be traced and connected to different user profiles. Students, informal scholars and occupational users - those actively occupying their time in a useful way in the library, whether working for a salary or not - use mostly tables, grouped in twos or in rows and Internet workstations. They sometimes resort to tricks (Certeau, 1990) to create additional, reserve space, scattering personal belongings and books over neighbouring places, signalling they are not willing to share it. This silent competition for space may be based on assumptions on what adequate uses and users are. Students seem to have their presence legitimated by their activity, envisaged as a 'natural' and sufficient reason by staff and other users.

A special group in this library is formed by 'residents', an epithet created by local staff for habitués readers who visit it, sometimes daily, staying for several hours, frequently privileged with special attention paid by some librarians, especially if they are elderly people. They tend to congregate around the tables surrounding the mezzanine, a spot that allows for optimal visual control over the whole space. An anecdotal case may, in spite of its singularity, depict how they feel entitled to this special attention as frequent users; an elderly male reader once asked the staff to have his own sofa, which he had already brought in, placed in front of his usual table because he felt it was more comfortable than the library's.

The library is acknowledged as a safe place; surveillance activities and the presence of cameras, which none of the interviewees had noticed before their attention was drawn to them, are felt to be protective measures. The number of cameras was intentionally low because the library wanted to 'respect the privacy of users' (building maintenance officer). The homeless reader says: 'I like closed premises best where tranquillity is to be found'. The socially frail are also found to be the ones appreciating safety the most. Lockers in the lobby are not used much. The staff advises the use of security lock chain cables for portable PCs as thefts were registered some years ago, but nowadays the situation is under control.

A story, often told, of a fight between readers involving a gun was not confirmed by the building maintenance officer; it is just another urban legend among many others in the city, which may be explained by subjective feelings of insecurity, associated with the belief of the danger of urban space (Fernandes, 2003). Crossing the garden, even after sunset, did not seem to arouse fear. The only exceptions were a blind reader, who occasionally needs assistance to reach the gate through its winding paths, and an older reader with a locomotion disability.

The building security and maintenance officer sums up the problems and solutions adopted thus:

Right now there were only a few interventions there ... We have guys from Eastern Europe who go to the multimedia area and use couches to watch films and go there to sleep ... These are the most annoying situations we have ... We had four TV sets and cut them down to two, trying to reduce the entry of users ... we cannot deny them entrance because we are a public service but we must avoid them ... it only creates some problems with other people who want to use the same equipment which makes some sense.

There were also some problems with kids who stole all the mouse balls in the children's section from us, it was a prank, it was more to draw attention. Apart from Eastern individuals and some with alcoholism issues who came around ... and keep on coming ... We cannot intervene [in alcohol abuse situations], we cannot throw people out for that reason. We signal our presence through a security agent, they wake up, complain, sometimes we have written complaints from users, we can't do anything else. One of the characteristics of this space is to be public, open to all kinds of public, we cannot discriminate, we have to live with it, we must be very cautious.

He finally adds that, in general, the amount of people visiting the library reflects the fact that readers are allowed to move and browse freely:

If there is an excess it's because the offer is good. The facility, when designed, was never envisaged as being so crowded and so well accepted.

The building itself presents no accessibility issues, according to a blind reader and to an older man with mobility issues, using crutches. The couple with the prams also evaluated this issue positively as they had been told they could use the lift.

\section{Social regulation of conduct: 'To do what this was meant for'}

A formal rule on the use of reading areas is waiting for management approval; its absence might lead users to believe that informal use was thus being favoured. Some specific rules are in force only for domestic borrowing and for the use of Internet stations.

According to field observation, however, a different reality was to be found: some readers behave, expect others to behave, or even urge them to comply with behaviours 
according to what they consider to be legitimate practices. Similar results are reported by McKechnie et al. (2006) in two public libraries in Ontario where readers, not staff members, occasionally shushed other readers.

By their usual access to staff and the places they choose to sit, residents, along with other frequent readers, seem to have a decisive role in the production of an implicit conduct regulation code.

A resident reader explains why she preferred this to another library near her home, in a neighbouring city:

Here people [...] are civilized, not there! [...] This is a high category library, the other is a fishwives thing, I don't get involved in those conflicts because I'm a well-bred person. [...] Over there, it's typical, it's a small community, they make telephone calls, they go there to flirt, flirt at the end of the room, they go there and do everything except what it was meant to, I've already written to the Mayor on this.

She also states that she likes to find this multicultural environment, similar to the one she found in United Kingdom libraries: 'because here you find all kinds of people, Easterners and all'; however, she dislikes the presence of 'exceptions':

these people, these junkies, these homeless who go there [multimedia floor] and make a fuss when it ends [the time available for each reader], because they come to sleep and they even mess with people there.

Readers were observed sleeping on the couches, and the staff woke them, usually by intentionally dropping books, while the other readers did not look disturbed by their conduct. Front office staff mentioned they had problems with the homeless who used to go to the restrooms to bathe or who were sometimes drunk, as with Eastern European immigrants; this required security intervention. They had problems with the over-relaxed attitudes of some who took their shoes off while watching films, which required them to intervene. But what really seems to disturb some readers and staff members the most are the people from those social groups who were uncommon in public reading spaces, 'these exceptions' as they are referred to, and who seemed to be thought of as an illegitimate presence according to social class prejudices. Deprived of the necessary credentials of cultural and educational capital they are assumed to 'do everything except what [the library] was meant for'.

The decision to remove some TV sets formerly used to watch DVDs at will, eventually reinforced the social stigma associated with supports and means considered to require less educational capital than the traditional yet consecrated support, the book, a stigma that extended to the whole multimedia space. An international truck driver prefers this floor for being 'more for leisure', while 'up there is more for reading'. Attitudes, bodily postures and manners, demarcate different areas through embodied cues of a dominant corporal hexis (Bordieu, 1977), leading readers to choose their place according to social class perspectives of expected practices. These signs of domesticlike relaxation should not be understood as a complete lack of awareness of being in a public place. Readers refrain from some activities, such as visiting erotic websites, which they indulge in when at home. Here we are confronted with different notions of what is acceptable behaviour, according to diverse corporal hexeis, with the limits between public and private becoming blurred and, therefore, occasionally generating conflicts.

When resources are scarce, as is the case with newspapers and Internet stations, readers compete for them, making way for tactics of favourable positioning and even for races. Staff intervention is directed to instil patience and order in these periods of waiting time.

\section{The trialectics of Almeida Garrett's space}

As previously noted, space should be read according to a three-dimensional, combined perspective, following Lefèbvre and Soja: through the trialectics of perceived space, or first space, conceived space, or second space, and lived space, both material and immaterial, or third space.

\section{Perceived space: A flexible building}

The library's insertion in an old park, some decades ago the location of a funfair and luna park, propitiates informal uses, leisure reading and conviviality. Being in this park is being away from the city's hustle. Entering the library, readers still feel in contact with the outside space, the garden remaining in the back of their minds.

A first impression and reflection emerges from the building's clean forms; its simplicity allows an easy reading of the whole space and of particular places, and also encourages individual appropriations. This building reveals itself as flexible to interpretation, in the sense that it reflects the architect's concerns with actualization and individualization. The architect emphasized the flexibility of the design which users clearly take full advantage of, as observed. Readers from different ages, sexes and social classes all seemed to appreciate this design; were it not so clean, it might not have encouraged the same results.

The way users underestimated some problems with ventilation and temperature or declined to point out any other environmental positive or negative characteristics, apart from noise, were the result of a very positive overall opinion of the services provided. The Portuguese history of public reading, with open and direct access to books, with free broadband access to the Internet is still a short one; the large network of modern public libraries has only been 
around for two decades. This recency positively impacts on the evaluation of this 'good novelty'.

\section{Conceived space: Different visions of 'library'}

A short note on what some of those people think a library is may be helpful to give a thicker context to their narratives. As an aid, after freely expressing what they think a library is, interviewees were asked whether they would associate this space to any other known space, namely home, a bookshop, a school, a café.

Not surprisingly, most students conceive the library as a place to study, to seek information, a place expected to be quiet, conceptually similar to a school. In another user group, those indulging in self-study and with local history as a common research subject and composed of middle aged to elderly persons, a reader refers to the library as a place for memory, an elderly one defines it as a 'cathedral of culture', open to everyone, unlike 'consumption cathedrals'. For other readers, those who go there to spend time actively, to browse along the shelves and occasionally pick some items, and for those who go there to play, the library is conceived as a safe, comfortable place for entertainment, an alternative to one's home and additionally a place with conviviality opportunities. Or, differently from home, and from the point of view of the poor young couple living in a cramped apartment, a space with the very fine quality of privacy. Children were approached by asking them to draw a library. Colourful drawings and joyful attitudes completed their definition of a library as 'multicoloured', 'a wall and books are there in their place', but where computer and computer games are also expected to be found. Playfulness and order were the characteristics most commonly mentioned. A reader usually going to the library to watch films, access the Internet or read magazines, 'more to feel relaxed' than 'to read', associates its space with a cinema, reminding us that some social interaction was also available in it.

The need for silence, while primarily a functional need, revealed itself to be an important cultural marker, closely intertwined with cultural capital in the learning and compliance to rules, tacit in this specific case and of practices considered to be legitimate, those prescribing what a library is meant for. Accordingly, different expectations give way to different behaviours, with some users, if not the staff themselves, acting to control these features.

Asked about their self-representation as visitors using library services, they opt to be named users - 'as in a health care [public] centres' - or to a lesser extent, readers. Only one hesitated as to whether she might also be a customer, since she feels she also pays for health services. The public service label is clearly attached to their statements; this space is conceived distinctively as a public one.

At this point of reflection, it is important to remember that conviviality or leisure in the library are values not altogether widely accepted. Both management and staff showed a general approval of such practices in this particular library. But still a security officer wondered how some readers spend so much time there, 'it seems they have nothing else to do!'.

\section{Lived space: Socially interacting while making place}

Simplicity in forms and materials reinforces the building's availability to be 'customized' to individual users' needs and tastes, displaying a diversity of unique spaces, on a par with the 'grand central nave and side chapels' in Jesuit churches, in Soares' own words, offering users 'a mix of a great space and small particular spaces'. We should note that the management's attitudes towards users' appropriations also foster these tendencies in space use.

The fact that the library may be read as a whole, without imposing divisions between different functional and age areas, also allows for the perception of the social and age diversity that some users made a point of positively underlining in their statements. It also clearly allows for the construction of a feeling of togetherness, seeing others absorbed in their tasks stimulates concentration in study, as users also stated. The much appreciated light and transparency were interpreted, as stated above, as tightly associated with feelings of tranquillity and practices of open, free access to resources. Personalization, conviviality, as also discussed, were similarly found to be important dimensions in the way this space is lived, or, to use Lefèbvre's terminology, produced and reproduced by users themselves.

\section{Building a reading atmosphere: To be 'en su sítio'}

It was very interesting to notice that environmental, comfort issues tied to the architectural design were not raised by readers and they did not make any remarks about light, sound, temperature or furniture. Although, as the architect remarked: 'it's the kind of things that people don't notice but it's what imprints character' on the building.

It was interesting and, above all, it was meaningful. It is suggested that people may not be aware of these details but may still sense them, while tending to express their impact in a combined evaluation of the whole environment, in a blend of physical/sensorial and psychological/affective dimensions. It must, nevertheless, be stated that this library was well conceived and that the architect's attention to 'those kinds of things' appears to be well reflected in the very pleasant atmosphere achieved, with the admitted exception of poor ventilation in some areas.

And, simultaneously, many readers seemed so pleased to be able to use such high quality services for free that these issues might be envisaged as negligible, in some sort of trade against the very positive evaluation of the services 
provided and the acknowledgement of their scarcity and recency. The availability of these public services and their free-of-charge provision was sometimes not even taken for granted, a fact to which older readers were particularly sensitive.

The very positive evaluation made by users of the building and its atmosphere is related to several aspects, from the clarity and social sensitivity of the building programme's main concepts to the widely recognized high quality of the architecture, the excellent environment created by the garden, but also to the care and welcoming friendliness transmitted by staff, as readers made a point to stress.

Nevertheless, some complaints were made about noise made by other readers. A correct, desired balance of silence/ noise was subjectively defined and aural conditions were differently evaluated. Although some form of personally defined balance is required to achieve the concentration necessary for an introspective activity such as reading, it became very clear that those complaints were not so much about the absence of silence but more about the absence of 'adequate' attitudes which might denote that those others were fit for being in such a place. The acquired ability of knowing how to be 'en su sítio' was clearly a fundamental dimension, a credential of cultural capital necessary to be a qualified member. Tolerance towards noise made by children may also be interpreted as the acknowledgment of ability still in the making, of a necessary apprenticeship. A reading atmosphere is then clearly a product of a negotiation of behaviours, meanings and tacit rules. 'Itself the outcome of past actions, social space is what permits fresh actions to occur, while suggesting others and forbidding others yet' (Lefèbvre, 2000: 88-89). Audio technologies are frequently used in the production of such an atmosphere, operating both on its physical and interactional dimensions.

'Reading atmosphere' is therefore the term proposed to describe the collective weaving of a public reading context. The term is used to describe this multidimensional reality that interviewees found difficult to put into words, but which they felt and transmitted in different and sometimes unexpected ways. The fact that users could not easily dissect and separate all the conceptual dimensions involved, the fact that sensations, feelings, practices and judgment, individual and group appropriations, interests and values all agglomerate in the production and reproduction of a particular reading atmosphere suggests that it should be described in a similar way, so that social actors and actresses' own perspectives are taken into account (Haraway, 1988). The whole meaning attached to it might otherwise be lost in the translation into scholarly discourse (Taylor and Bogdan, 1984).

Describing and conceptualizing a public reading context requires a report that accounts for physical spatially, social interaction, power imbalances, feelings, behaviour negotiation, reader status consideration, environmental appreciation and the making and pondering of social rules. This concept of blurred boundaries is an amalgamated product of lived spatiality.

The prolonged observations and reflection developed in this single case study were made possible by the very nature of the methodological options made for this research. Focusing intensively and for a long period of time on a sole case allowed good conditions for this kind of reasoning and interpretation, difficult, if not impossible, to produce under different circumstances.

\section{Recommendations}

The design of separate reading zones by resource type and the fact that those using the multimedia area are less qualified resulted in a spatial segregation which, though not sharp, is still visible to readers themselves. The segregation that the architect wished to avoid is eventually exerting its effects by processes not spatial but of a cultural capital nature, resulting in the multimedia area, located are a lower level, being associated with inferior forms of reading.

In spite of, generally, a very good evaluation made by readers, some changes ought to be made in the multimedia area, namely reinstalling the removed TV set and having it play films according to a programmed schedule which might incorporate users' suggestions. This way all the equipment could be in use, more films could be viewed and conflicts over the individual appropriation of TVs could be diminished.

Special personal attention should be paid to most socially deprived readers so that all are accepted and all may feel welcome.

\section{Conclusions}

The social production of a reading atmosphere in Almeida Garrett is based on a tacit code of conduct, within a social class framework, with some readers, particularly the 'residents', acting as influential gatekeepers. Regulations were apparently sustained more by pressure from some readers than by institutional rules which, as mentioned, are still minimal.

Although sound conditions were especially appreciated, the social weaving of a good reading atmosphere goes much beyond aural conditions. Readers' complaints and evaluations included behavioural cues tied to cultural habitus and social class, revealing that, at least for some, an adequate atmosphere was equated to one where imagined legitimate practices were embodied. On the other hand, what is now tacit is certainly what was institutionally sought and eventually became a common practice under a convergence of interests. So the fact that the library does 
not have rules about behaviour does not mean that social control is absent; it is really just being conveyed and staged under other forms.

Freedom of movement and a relaxed atmosphere inside the building, free-access to documents, conviviality, staff friendliness and the possibility for users to personalize projected space all contributed positively to the popularity of this library.

\section{Funding}

This research is the partial result of the author's doctoral thesis which was funded by the Fundação para a Ciência e Tecnologia, under the POPH programme.

\section{References}

Bertrand A-M (1994) Cris et chuchotements. Bulletin des Bibliothèques de France 39(6): 8-13.

Blumer H (1969) Symbolic Interactionism. Englewood Cliffs, NJ: Prentice-Hall.

Bourdieu P (1977) Outline of a Theory of Practice. Cambridge: Cambridge University Press.

Bourdieu P (1979) La Distinction: Critique Sociale du Jugement de Goût. Paris: Éditions de Minuit.

Bourdieu P and Darbel A (1966) L'Amour de l'Art: Les Musées et leur Public. Paris: Éditions de Minuit.

Bull M (2006) Investigating the culture of mobile listening: From Walkman to iPod. In: O'Hara K, Brown B (eds) Consuming Music Together: Social and Collaborative Aspects of Music Consumption Technologies. Dordrecht: Springer, 131-149.

Burawoy M (1998) The extended case method. Sociological Theory 16(1): 4-33.

Certeau M de (1990) L'Invention du Quotidien: Art de Faire. Paris Gallimard.

Donmoyer R (2000) Generalizability and the single case study. In: Gomm R, Hammersley M, Foster P (eds) Case Study Method. Thousand Oaks, CA: Sage, 45-68.

Eigenbrodt O (2008) Designing library facilities for everyone? Providing space for informational participation.Paper prewsented at BOBCATSSS 2008 Symposium Providing Access to Information for Everyone, Zadar, Croatia. Available at: http:// edoc.hu-berlin.de/conferences/bobcatsss2008/eigenbrodt-olaf -89/PDF/eigenbrodt.pdf.

Fernandes L (2003) A imagem predatória da cidade Etnografias Urbanas. Oeiras: Celta, 53-62.

Finlayson A (2008) No shushing in this library. San Diego Reader, 18 June.

Fortuna C, Antunes L, Lopes JT, Cruz SA, Fontes F, Monteiro A, Aleixo A and Pinto RP (1999) Sobre a Leitura. Lisboa, IPLB: Observatório das Actividades Culturais.

Freitas E de, Casanova J L and Alves N de A (1997) Hábitos de Leitura: Um Inquérito à População Portuguesa. Lisboa: Dom Quixote.

Geertz CC (1975) The Interpretation of Cultures: Selected Essays. London: Hutchinson.

Given LM and Leckie GJ (2003) 'Sweeping' the library: Mapping the social activity space of the public library 1 ,
(November 2001). Library and Information Science Research 25(4): 365-385.

Gubrium JFH, and James A (eds) (2002) Handbook of Interview Research: Context and Method. Thousand Oaks, CA: Sage.

Haraway D (1988) Situated knowledges: The science question in feminism and the prrivilege of partial perspective. Feminist Studies 14(3): 575-599.

Haraway D (1991) A manifesto for cyborgs: Science, technology and socialist feminism in the 1980s. In: Haraway D Simians, Cyborgs and Women: The Reinvention of Nature. New York: Routledge, 149-181.

Kvale S (1996) Interviews: An Introduction to Qualitative Research Interviewing. Thousand Oaks, CA: Sage.

Lakatos I (1978) The Methodology of Scientific Research Programmes. Cambridge; New York: Cambridge University Press.

Lefèbvre H (2000 [1974]) La Production de l'Espace. Paris: Anthropos.

McKechnie L, Dixon CM, Fear J and Pollak A (2006) Rules of (mis)conduct: User behaviour in public libraries. Paper presented at the 34th Annual Conference of the CAIS-ACSI Information Science Revisited: Approaches to Innovation, York University, Toronto, 1-3 June. Quebec: Canadian Association for Information Science. Available at: http://www. cais-acsi.ca/proceedings/2006/mckechnie_2006.pdf.

Mattern S (2007) Resonant texts: Sounds of the contemporary American public library. The Senses \& Society 2(3): 277-302.

Miribel M de (2007) 'Chut! Vous faites trop de bruit!': Quel silence en bibliothèque aujourd'hui? Bulletin des Bibliothèques de France 52(4): 76-83.

Patton MQ (1990) Qualitative Evaluation and Research Methods. Newbury Park, CA: Sage.

Petit M (2001) Lecturas: Del Espacio Íntimo al Espacio Público. México: Fondo de Cultura Económica.

Seale C (ed.) (2004) Researching Society and Culture. London: Sage.

Soja EE (1996) Thirdspace: Journeys to Los Angeles and Other Real-and-Imagined Places. Cambridge, MA: Blackwell.

Taylor SJ and Bogdan R (1984) Introduction To Qualitative Research Methods: The Search for Meanings. New York: Wiley.

Webber MM (1963) Order in diversity: Community without propinquity. In: Wirigo L (ed.) Cities and Space: The Future Use of Urban Land. Baltimore, MD: Johns Hopkins University Press, 23-54.

\section{Author biography}

Paula Sequeiros has a degree in History, a postgraduate degree in Documentary Sciences, a Masters Degree in Information Society and Knowledge and a Doctorship in Sociology. She was a special librarian in commercial banks for 20 years and a former University Library Director with the Catholic University of Porto. She has worked as a lecturer and trainer in library and information services since 1987. Since 2005, she has been an Editor and, since 2011, a member of the Executive Board of eLIS, an Open Access Archive in Library and Information Sciences. 